\title{
Parental Effectiveness and School Counselling in Elementary Education
}

\author{
Demetriou Loukia ${ }^{*}$ and Kalouri Ourania ${ }^{2}$ \\ ${ }^{1}$ Associate Professor of Psychology, Frederick University, Department of Psychology and \\ Social Sciences, Frederick University, Cyprus \\ ${ }^{2}$ Professor of Education, School of Pedagogical and Technological Education, ASPETE, \\ Greece
}

\begin{tabular}{l} 
ARTICLE INFO \\
\hline Keywords: \\
Parental Effectiveness \\
Parenting Skills \\
Primary Education \\
Positive Parenting \\
School Counselling
\end{tabular}

1. Introduction

According to the American Psychological Association, parenting practices around the world share three major goals: ensuring children's health and safely, preparing children for a life as productive adults, and transmitting cultural values (APA, 2018). Some of the experience's children have are random - not planned or organized by any outside agency - but some occur according to what might be called a socialization timetable. According to Maccoby (2000) there is increasing emphasis on the role of parents' and children's mutual perceptions and understandings about each other's dispositions and intentions as determiners of their influence

\begin{abstract}
Parenting today is as challenging as ever. People grow into their parental role, and develop their parenting skills as they counter challenges and apply daily routines in response to their children's needs. Parental effectiveness is significant in the behavior that parents show during the interactions with their children as well as during the entire socialization process. Parents of young children are responsible for their care, their physical safety and for their physical, cognitive and emotional development; they micromanage the child's inclusion in society and cultivate his/her socially acceptable behaviors. If they feel that they are efficient at their role as parents, then the child's cognitive and psychosocial development is enhanced. Counselling at the primary school level could enable parents to better manage problematic situations that arise with their child's learning and/or tional needs by providing in-school parental education sessions would facilitate parents to improve their parental skills. This study aims to (a) investigate and measure parental effectiveness and (b) research the perception of parents of primary school children regarding the necessity to implement school Counselling in the Cyprus Elementary School System. A sample of 120 parents of children 6-12 years old, in Limassol, Cyprus, answered two questionnaires, namely the Alabama Parenting Questionnaire (APQ) and a questionnaire we constructed to examine parental attitudes on Elementary School Counselling. Results show that parental effectiveness is significantly influenced by the educational background of the parents, the mother's age, the status of the family, the number of children in the family and the gender of the child. At the same time, our results indicate that the majority of the participating parents acknowledge the importance of early Counselling interventions in parental educational programs at the primary education level.
\end{abstract}

\footnotetext{
* Corresponding Author E-Mail Address: luciad61@gmail.com 
upon one another. However, none of these theoretical shifts has greatly affected the underlying assumption that parents have a powerful impact on the characteristic's children develop and the directions their lives take. A great body of research focuses its questions on factors such as: (a) familial risk factors (i.e. aspects of family functioning); (b) social conditions that affect parenting practices (i.e. how well parents are able to monitor their children, or how warm and responsive they are); and (c) parenting behaviors as mediators of the connection between societal risk factors (e.g. poverty or dangerous neighborhoods) and children's adjustment (Maccobi, 2000). Parental Effectiveness, namely parents' perception of efficacy to fulfil the parental role, may be enhanced substantially through his/her participation in Parental Education Programs. According to the American School Counselling Association (ASCA), school counselors work on promoting systemic change in children's lives through collaborating with and involving parents, teachers, community members and students in the development of comprehensive school counseling programs that promote children's growth and development. When it comes to the overall wellbeing of children, school counselors play an important role in facilitating the academic, career, and personal/social development of the children at their schools (Bowers \& Hatch, 2012).

Consequently, counselling at the primary school level could help parents to both prevent and manage problematic situations that arise with their child's learning and/or emotional needs. Studies support the use of parenting programs to improve the short-term psychosocial wellbeing of parents (Barlow et al., 2014). Furthermore, a number of meta-studies provide evidence that programs intended for selective prevention do contribute to, or strengthen, good parenting as well as improve moderately harmful or ineffective parenting (Barlow et al., 2014; Furlong et al., 2012; Kaminski et al., 2008). Teachers at the primary school are often required to take roles outside of their teaching work in order to help parents cope with children's unwanted behavior or to help children cope with their parents ineffective parenting skills, roles for which they are insufficiently trained. Once again, we are faced with the discussion on the necessity for school counselling services at the public elementary school level in Cyprus (Dimitriou, 2014). One of the essential functions of Counselling is to act preventively. Consequently, the development, the implementation and the impact of programs in effective parenting could be part of the focus of the School Counsellor's responsibilities at the elementary school level. However, in the Cyprus public school system, school counselling does not begin until the 2nd grade of high school, when children have already reached the age of 14, so programs that would enhance parenting skills cannot be made available for all the parents through the public-school system.

In this study we examine how factors such as parental gender and education, children's gender and birth order, the structure and socioeconomic factors of the family affect Parental Effectiveness. At the same time though, we research parents' attitudes and opinions on the potential effectiveness of school counseling programs in the elementary school as facilitators of programs to enhance parental effectiveness.

\section{Theoretical Background}

\subsection{Parenting and its effects on children}

All societies expect their members to possess certain characteristics if they are to function adequately as members of these societies. Some of these prescriptions and proscriptions are according to Maccobi (2000) nearly universal across cultures, such as the requirement for parents to provide nurturance and protection for children. Other standards and values vary from one culture to another. However, in all societies, certain procedures are followed, including training, behavior management, placing social controls to ensure that children are socialized, i.e. brought up in such ways that each new generation acquires the prescribed patterns of beliefs and behaviors [ibid]. 
In western societies, we can identify at least three major contexts in which childhood socialization takes place; families, peer groups and schools. The role of parents has been the focus of many studies in the last decades; during childhood (6-11 years of age) children are open to social influences on characteristics that they will acquire and keep long after they have left their family of origin. Research on child development has been focusing on a wide range of issues, as (a) familial risk factors, (b) social conditions that affect parenting practices the warmth dimension in parenting $(\mathrm{d})$ parenting behaviors as mediators of the connection between societal risk factors and children's adjustment.

Research findings in the 1990s show significant associations between parents' attributes and children's behavior, i.e. Patterson (1995) reports substantial correlations between parental characteristics (e.g. disciplinary practices and monitoring) and children's antisocial behavior. Their research shows connections between parental behaviors and children's negative, coercive behavior both at home as well as in out-of-home contexts (Patterson \& Forgatch, 1995). Hetherigton and her team (1999) discuss a concurrent coefficient of 0.76 between mothers' "authoritative parenting" and adolescents' "social responsibility". More recent studies have also found consistent links between parenting and child behavioral adjustment. For example, a mother's parenting behaviors, including the extent to which she shows affection toward and exerts behavioral and psychological control over her child, when the child is five years of age, are linked to later child internalizing and externalizing behaviors (Aunola \& Nurmi, 2005). Internalizing, or emotional, behavior problems often refer to anxiety and depression, while externalizing, or disruptive behavior problems commonly include attentiondeficit hyperactivity disorder and conduct problems (Akhter et al., 2011). These are just a few examples showing behavioral patterns that are, in part, influenced by particular styles of parenting.

\subsection{Parental Effectiveness}

An important aspect in the study of parenting is parental effectiveness. Parental effectiveness refers to the parent's perception of his/her efficacy to fulfill the parental role (Johnston \& Mash, 1989). The concept of efficacy plays a significant role in the behavior that parents show during the interactions with their children and is closely related to the cognitive and the psychosocial development and adaptation of the child (Jones \& Prinz, 2005). Furthermore, the concept of satisfaction with the parental role is closely related to parental efficacy and consequently to parental effectiveness. Parental satisfaction refers to the pleasure and the sense of satisfaction that the parent feels as a result of performing the daily duties that are related to the care of his child (Printham \& Chang, 1989). Research shows that low parental efficacy and satisfaction from the parental role are closely related with parental fatigue as well as stress in the parents' effort to fulfill daily parental duties and responsibilities (Coocklin, Giallo, \& Rose, 2011).

Parental attitudes and practices that characterize the interrelationship between parent and child in various circumstances are summarized under "parental style". As this relation is multidirectional, the study of the influence of parenting practices over child behavioral outcomes become quite complex. For example, in a study of adolescents' perception of their parents 'psychological control of their emotions and beliefs, Albrecht, Galambos, and Jansson (2007) found child behavior as a stronger predictor of changes in parental psychological control than parental behavior as a predictor of changes in adolescent behavior. A common way of addressing these complexities is by organizing parenting behaviors into Baumrind's four distinct parenting styles, namely authoritarian, permissive, uninvolved, and authoritative (Maccoby, \& Martin, 1983). These four parenting styles are based on two parental dimensions, "parental warmth" otherwise known as parental acceptance (Rohner, 1991), which is related 
to parental affection toward and acceptance of the child, and "parental control", which is related to the role parents play in promoting respect for rules and conventions [ibid.].

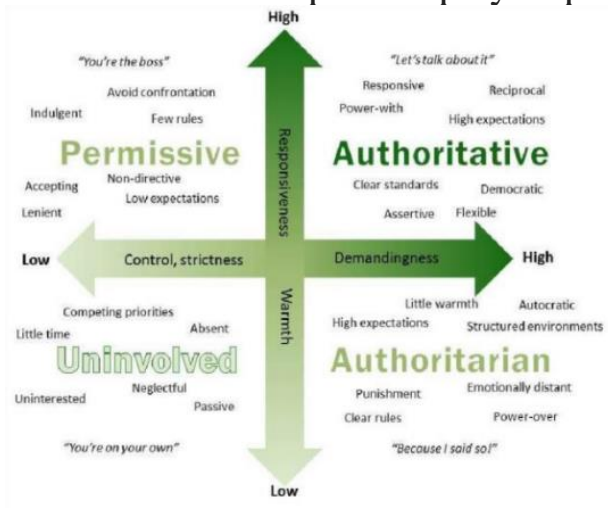

Figure 1: Two-dimensional model: Schaefer/Baumrind Parenting Styles and Parental Behavior toward Children

Figure 1 illustrates the type of child rearing that can be described by classifying parents' behavior on warmth-acceptance (the vertical axis) and restrictiveness-permissiveness (the horizontal axis). The labelled points in each quadrant of Fig. 1 show how a parent might behave when showing different combinations of warmth-acceptance and restrictiveness. For example, a parent who is rejecting and restrictive might be labelled as demanding and as antagonistic. A permissive, rejecting parent could be considered indifferent while a permissive, accepting parent might be characterized as democratic. The meanings of these rather abstract terms can best be garnered from a closer examination of the types of parent behavior and attitudes involved (Demetriou \& Christodoulides, 2006). There has been extensive research on the implications parenting styles have on behavioral outcomes in children. According to Baumrind (1991) authoritarian parenting has been associated with child outcomes such as hostility, delinquency, rebelliousness, and antisocial aggression (Baumrind, 1991). Research has also revealed that a child's early experience with excessive parental control tends to correlate with the development of anxiety (Chorpita \& Barlow, 1998). Parents with a permissive style have a tendency to be very loving and nurturing, but also allow their children to solve problems without parental involvement (Baumrind, 1991). In a study of permissive parenting, lack of involvement, lack of follow through, and lack of confidence in parenting ability were important predictors of child behavior problems reported by both parents and teachers (Calzada, 2001). The uninvolved parent combines low levels of warmth and low levels of control, and does not apply any specific discipline style. Communication is limited, nurturance is low, and the child, generally, has an excessive amount of freedom (Baumrind, 1991). Because the uninvolved parent is neither demanding, nor responsive, and because young children are highly dependent on parental structure and support, uninvolved parenting has been associated with behavioral problems and depression in children (Downey \& Coyne, 1990). The authoritative parents show both high levels of warmth and high levels of control, they are reasonable and nurturing, set high expectations, explain disciplinary rules clearly, and engage in frequent communication with their children. Authoritative parenting has been associated with greater child competence, exceptional maturity, assertiveness, and self-control (Baumrind, 1991).

\subsection{Counseling for Parental Effectiveness}

In today's world Brouzos (2009) considers Counseling to be an imperative need for the children in all levels of the educational system, given the speed at which socioeconomic circumstances change both for societies as well as for the individuals that live in them. In southern European countries, such as Cyprus, due to a long-lasting period of economic crisis, 
social problems, such as unemployment, and even homelessness have multiplied. In view of the fact that many families face impasses, parents encounter increasing responsibilities as well as difficulties in performing their parental role and duties toward their children. Teachers at the primary school are often required to take roles outside of their teaching work in order to help parents cope with children's unwanted behavior or to help children cope with their parents ineffective parenting skills, roles for which they are insufficiently trained. Once again, we are faced with the discussion on the necessity for school counselling services at the public elementary school level in Cyprus (Dimitriou, 2014) which could provide parents with intervention programs in parent education. Indeed, some parents may need additional support and guidance to better understand child development, to respond appropriately to their child's needs, and to cope with the challenges of parenting. Parent education reduces the risk of child abuse and neglect by encouraging positive parenting practices that promote safety, well-being, and permanency for children and families.

The Child Abuse Prevention and Treatment Act (CAPTA) (Child Welfare Information Gateway, 2019) as reauthorized in 2010, identifies parent education as a core prevention service. Parent education provides caregivers with knowledge, resources, and support to develop parenting skills to enhance child and family well-being. It can also help parents or caregivers learn the tools and strategies to provide a positive and nurturing home environment where their children will thrive physically, emotionally, and cognitively. Research findings show evidence that Parent education programs have significant benefits for parents, caregivers, children and families.

According to the Wilder Research (2016) some of these benefits are seen in the following: (a) The increase of positive parenting style, as a result of greater understanding of child development and effective communication styles, (b) enhanced social connections as parents exchange ideas, provide and obtain support and share resources, (c) improvement of parental skills, resulting in improved child behavior, as children whose parents take part in these programs display an increase in prosocial behaviors and a decrease in negative externalizing behaviors (d) improvement in quality parent-child interactions as a result of parents learning how to engage with their children, (e) enhanced parental mental health and well-being, as improved skills and parenting knowledge help to reduce caregiver depression, anxiety, anger, guilt, and stress, (f) reduced risk of corporal punishment and child abuse as parents learn alternatives to physical punishment and a new way of thinking about appropriate family roles and expectations of children, (g) $f$ parental self-confidence and empowerment as caregiving skills progress and parents grow more competent and comfortable in their roles [ibid.].

Which are the elements that make Parent Education Programs effective? According to the US Child Welfare Information Gateway (2019) certain program characteristics and practices help make parent education programs successful. Indeed, there is no "one-size-fits-all" approach. Programs need to address community and cultural needs; have available staff and adequate resources; and, where possible, offer individualized counseling interventions for the parents and children at risk of potential or repeated maltreatment. The US National Academies of Science, Engineering and Medicine (NASEM) have compiled the following list of elements that a Parent Education Program may include that will ensure its success. These suggestions include: Providing parents with an opportunity to network with, and receive support from, parents who are in or who have been in similar circumstances; treating parents as equal partners when determining which services would be most beneficial for them and their children; $f$ tailoring programs to the specific needs of families; $f$ addressing trauma to ensure that it does not interfere with parenting and healthy development; ensuring that families with multiple needs receive coordinated services and offering programs that are culturally relevant to meet the needs of diverse populations [ibid.]. 


\section{Methodology}

\subsection{Hypotheses}

This study aims to (a) investigate and measure parental effectiveness in regards to factors that might be affecting it such as the age and the gender of parents, the gender of the child, parental education, number of children in the family and family situation and (b) research the perceptions of parents of primary school children regarding the functions and the necessity to implement school Counselling in the Cyprus Elementary School System as a means to improve their parental effectiveness.

Based on these aims, we tested the following hypotheses:

(a) Parental education, the parents' age, the family situation and the gender and number of children in the family do not influence parental effectiveness and

(b) Parents knowledge and attitudes toward the introduction of School Counseling in the Cyprus public elementary school system will determine their opinion on the potential effectiveness that school counseling programs may have in enhancing parental effectiveness.

In order to describe the characteristics of the sample we applied descriptive statistics, such as the mean, the standard deviation, the frequencies and percentages. Data was processed and analyzed through SPSS. We tested for significance through the independent sample t-test for parents' gender, age, education and gender and number of children in the family to examine our Null Hypothesis (H0) that there would be no statistically significant differences in parents' perceived effectiveness dependent on the above-named variables. The level of significance was placed at $95 \%$ ( $\mathrm{p}$ value $=0,05)$.

\subsection{Sample}

We collected the data for this study from Greek Cypriot families, living in Limassol in the years 2017 and 2018. Our sample consisted of 120 parents, 86\% women and 14\% men, all parents of children in the age group from 6 to 11 years old. Regarding the level of education, it was established that the majority of the parents $(63 \%)$ had graduated from university whereas $37 \%$ had finished high school. Most of our participants were part of twoparent families (95, $5 \%$ ). The sample was recruited using various methods, including personal interaction as well as use of email and Social Media. The questionnaires were uploaded on the electronic platform Anketa (1KA), and the link was shared via email and Facebook. The aim and content of the study was explained to the parents through a small introduction on the cover of the questionnaires. Consent was requested before completing and submitting the questionnaire(s).

\subsection{Instruments}

In order to investigate the effectiveness of parental practices we used the Alabama Parenting Questionnaire (APQ) (Shelton, Frick \& Wootton, 1996; Wilder Research, 2016). A team of experts translated the APQ into Greek for the purposes of this study. This 42-item self-report questionnaire measures five dimensions of parenting: (1) positive involvement with children, (2) supervision and monitoring, (3) use of positive discipline techniques, (4) consistency in the use of such discipline and (5) use of corporal punishment. Subjects answer on a 5-point Likert Scale ranging from („never "to ,always “). The average reliability across the APQ scales is 0.68. In order to assess the demographics of our sample, but also to establish the relationship between the characteristics of the parents and their effectiveness we added five questions to our instrument. These related to age, gender, educational level, family status, number of children in the family and age of child(en).

Parental attitudes on Elementary School Counselling were assessed with the use of a questionnaire that we constructed for the purpose of this study. The instrument comprised of a total of thirteen (13) questions. Seven of these questions were multiple-choice questions, 
where parents had the option to choose more than one answer. The other six questions were answered on a Likert scale, where parents had to choose their degree of agreement to the content of these items. The options ranged from $1=$ "never" to $5=$ "always".

\subsection{Results of Alabama Parenting Questionnaire (APQ)}

Our results indicated that the child's age, the birth order, and the family's income (tested as independent variables) do not play a significant role in parental effectiveness.

However, in examining our first hypothesis, our research results show the following parameters do affect significantly the parental effectiveness of the participants in our sample.

\subsubsection{Parental Education}

The educational level of both parents is significant in predicting parental effectiveness in the five dimensions of the APQ. In the case of the father the results of the two-sample test show a significant difference between fathers with higher and fathers with lower education in the following dimensions: positive involvement with children, use of positive discipline techniques supervision and monitoring and in discipline $(\mathrm{p}<0,05)$. The only dimension of parenting in which higher education does not seem to predict the fathers' behavior is the use positive discipline techniques. Regarding the mothers of our sample the results of the twosample t-test show that the higher their education the more they show positive involvement, use more frequently positive discipline techniques, apply better supervision and monitoring and show more consistency in their discipline techniques. There is no significant difference between mothers with higher and those with lower education regarding the use of corporal punishment (Table 1).

Table 1.

Parental Educational Level and APQ Dimensions

\begin{tabular}{|c|c|c|c|c|c|c|}
\hline APQ Dimensions & $\begin{array}{l}\text { Fathers' } \\
\text { Educational Level }\end{array}$ & Mean & Sig. & $\begin{array}{l}\text { Mothers' } \\
\text { Educational Level }\end{array}$ & Mean & Sig. \\
\hline \multirow[t]{2}{*}{ Positive Involvement } & High School & 21.58 & \multirow{2}{*}{0.016} & High School & 17.41 & \multirow{2}{*}{0.011} \\
\hline & University & 2.43 & & University & 28.43 & \\
\hline \multirow[t]{2}{*}{ Positive Discipline } & High School & 14.93 & \multirow{2}{*}{0.063} & High School & 12.13 & \multirow{2}{*}{0.008} \\
\hline & University & 19.67 & & University & 19.68 & \\
\hline \multirow[t]{2}{*}{ Supervision } & High School & 2.89 & \multirow{2}{*}{0.021} & High School & 1.48 & \multirow{2}{*}{0.037} \\
\hline & University & 5.85 & & University & 5.73 & \\
\hline \multirow[t]{2}{*}{ Consistency in Discipline } & High School & 6.43 & \multirow{2}{*}{0.032} & High School & 4.58 & \multirow{2}{*}{0.035} \\
\hline & University & 9.12 & & University & 9.2 & \\
\hline \multirow[t]{2}{*}{ Corporal Punishment } & High School & 2.33 & \multirow{2}{*}{0.049} & High School & 1.58 & \multirow{2}{*}{0.064} \\
\hline & University & 3.76 & & University & 3.72 & \\
\hline
\end{tabular}

\subsubsection{Parental Age}

The statistical analysis of our results shows that age plays a significant role in the parental effectiveness of the mothers but not of the fathers of our sample. In contrast to the male sample, maternal age is a decisive factor for all the dimensions of the APQ in our women participants. In the sample of our mothers, $33 \%$ was in the age group 28-34 whereas $35 \%$ were $35-38$ years old and $33 \%$ were over 39 years of age. Our results show that mothers in the ages between 35 38 years, had significantly more parental effectiveness in all dimensions of the APQ compared to the mothers belonging to the other two age groups $(\mathrm{p}<0,05)$.

\subsubsection{Number and Gender of Children in the Family}

Regarding the effect of the number of children in the family on parental effectiveness we carried out the ANOVA test. Results indicate that the number of children in the family plays a significant role in all five dimensions of parental effectiveness of the APQ $(p<0,05)$. More 
specifically our results show that parents with two or with four children are able to perform their parental role with more effectively than parents with one child or with three offspring in the family. Additionally, the gender of the child(en) also plays a significant role in parental effectiveness (table 2). The results of the two-sample t-test show that the parents of boys are significantly more effective in the dimension's parental positive involvement and the positive application of discipline in comparison to the parents of girls $(\mathrm{p}<0,05)$.

Table 2.

Gender of the Child and Parental Effectiveness

\begin{tabular}{llcc}
\hline APQ Dimensions & Gender of Child & Mean & Sig. \\
\hline \multirow{2}{*}{ Positive Involvement } & Male & 23.93 & \multirow{2}{*}{0.042} \\
& Female & 28.70 & \\
Positive Discipline & Male & 16.58 & \multirow{2}{*}{0.071} \\
& Female & 19.90 & \\
\multirow{2}{*}{ Supervision and Control } & Male & 3.35 & \multirow{2}{*}{0.102} \\
& Female & 6.40 & \\
Consistency in Discipline & Male & 7.16 & \multirow{2}{*}{0.108} \\
& Female & 9.47 & \\
Corporal Punishment & Male & 2.88 & \multirow{2}{*}{0.43} \\
& Female & 3.63 & \\
\hline
\end{tabular}

\subsection{Results on Parental Attitudes on Elementary School Counselling}

Our second instrument was a questionnaire with thirteen questions in which parents were given either the option to provide more than one answers or they could choose their degree of agreement to the content of the questions on a Likert Scale from 1-5, where 1 implied total disagreement and 5 implied the highest possible degree of agreement.

\subsubsection{The functions of School Counselling}

The first question aimed at examining the degree of familiarity of our sample with the functions of School Counselling. In this respect, the parents were asked to assess whether various functions performed at and by the school constitute "School Counselling". In Table 3 we summarize our findings and present the answers that received the highest percentages on the Likert-Scale's option "completely agree", i.e. option (5).

Table 3.

Parental opinions on the functions of School Counselling

\begin{tabular}{lc}
\hline & Percentage \\
\hline 1. Integration of children in new environments & $77 \%$ \\
2. Creation of trustful relationships & $61 \%$ \\
3. Advise to the students and their parents & $\mathbf{5 7 \%}$ \\
4. Exploration of student's emotions & $57 \%$ \\
5. Student-Parent guidance & $\mathbf{5 5 \%}$ \\
6. Collaboration regarding pupils' problems & $\mathbf{5 1 \%}$ \\
7. Support for teachers & $47 \%$ \\
8. Evaluation of student performance & $47 \%$ \\
9. Cultivation of respect towards diversity & $40 \%$ \\
10. Solutions to students' problems & $39 \%$ \\
11. Facilitation of teacher-student collaboration & $26 \%$ \\
\hline
\end{tabular}

The parents' answers indicate that for the majority of the parents (77\%) student Counselling services at school facilitate the integration of children in new environments and help create trustful relationships between children and teachers $(61 \%)$. At the same time, their responses indicate their belief that the School Counselling services could provide useful assistance to 
families and parents. More than half of our sample believe that the School Counselling services aim at improving the child-parent relationship (61\%), have an advisory role for pupils and their parents $(57 \%)$, help children explore their feelings (57\%), provide student-parent guidance $(55 \%)$ and promote the collaboration between pupils, teachers and parents in the resolution of student's problems $(51 \%)$.

\subsubsection{Types of problems that School Counselling may resolve}

As far as the type of problems that School Counselling can help resolve, the responses of our participants show that to a great extent parents focus on family problems and the child's unwanted behavior (Table 4).

Table 4.

Types of Problems that School Counselling may resolve

\begin{tabular}{lc}
\hline & Percentage \\
\hline 1. Family problems & $67 \%$ \\
2. Behavioral problems & $67 \%$ \\
3. Conflicts between school staff & $37 \%$ \\
4. Conflicts between parents and school staff & $35 \%$ \\
5. Problems regarding violent behavior at school & $32 \%$ \\
6. Learning difficulties & $22 \%$ \\
\hline
\end{tabular}

The answers of the parents with the highest frequency indicated that our participants believe that the school counsellor(s) can help families to resolve their problems (67\%) and can be of great assistance when it comes to facing children's behavioral problems (67\%). Responses with significantly lower frequencies regarded that School Counselling services can facilitate conflict resolution between school staff members (37\%), conflict resolution between parents and school staff members (35\%), resolution of problems regarding children's violent behaviors $(32 \%)$ and last but not least can assist the child with learning difficulties (22\%).

The vast majority of our participating parents $(85 \%)$ believe that School Counselling will be more successful if it focuses on early prevention instead of on the resolution of the problem after it appears. As far as the conditions that would make school counselling interventions more successful, parents chose the option "completely agree" for (a) a good collaboration between the school, the parents, the pupils and the counsellor(s) (70\%), and (b) the academic qualifications of the counsellors (82\%).

\section{Discussion of Results}

In regard to our first hypothesis, we have enough evidence to tend toward its rejection. Our results show that indeed factors such as the parental educational level, the mother's age, the family situation and the gender and number of children in the family do significantly affect the parental perceived effectiveness.

The parental level of education is a decisive factor in perceived parental effectiveness. The fathers and mothers of our sample with university education have significantly higher scores on four out of the five dimensions of the APQ compared to the parents with a lower level of education $(\mathrm{p}<0,05)$. These dimensions are positive Involvement, supervision and consistency in the application of disciplinary methods for both genders of our sample. However, the parental level of education cannot predict the frequency of the use of corporal punishment, as the $p$ value for both fathers and mothers is higher than our significance level $(\alpha=0,05)$. Our findings as to the significance of the level of parental education in perceived parental effectiveness are in compliance with Family Process Models. Studies by Conger et al. (2002) and Mistry et al., (2008) have proposed that family structural variables such as parental education and income affect the level of actual interactions within the family, and 
concomitantly, the child 's behavior. They also show that the effects of socioeconomic stress (e.g., financial strain, unstable employment) on child outcomes are mediated through parenting stress and family interaction patterns. Kainuwa and Yusuf (2013) also have similar findings, namely that parents with higher education are not only more involved in their children's 'lives but they also teach them social and problem-solving skills. Furthermore, mothers with a higher level of education may give their children more educational opportunities, more attention and more priority to their needs (Booth \& Hiau, 2009).

According to our findings, only maternal and not paternal age is significantly important in perceived parental effectiveness in all five dimensions of the APQ. Our results show that mothers in the ages between 35-38 years have a higher perceived parental effectiveness than the mothers of all the other age groups of our sample $(\mathrm{p}<0,05)$. Our results are similar to recent findings by Kim et al. (2018). Their findings show that among advanced age mothers (35+ years of age) positive-interaction parenting significantly increased with social support, and decreased with depression, very good/excellent health, and older children (Kim et al., 2018). Our results indicate that the number of children in the family seems to be another significant predictor in all five dimensions of the APQ. Parents of two or four children report significantly higher perceived parental effectiveness than the parents of a single or of three offspring $(\mathrm{p}<0$, 05). However, it is not just the number of children in the family but also the children's gender that plays a significant role in parental effectiveness. Our findings show that the parents of boys (both fathers and mothers) feel significantly more effective than those of girls in the dimension's parental positive involvement and the consistent application of discipline in comparison to the parents of girls $(\mathrm{p}<0,05)$. In the same context Crouter, McHale and Bartko (1993) also found a tendency for boys and girls in different family contexts to respond differently to family experiences with mothers vs. fathers. In this regard, their data suggests that school-age boys may need more structure (e.g., parental monitoring, maternal involvement in joint activities) from parents than do girls (Crouter, McHale \& Bartko, 1993).

Regarding our second hypothesis, our findings provide evidence that it is verified. The parents of our sample seem to be familiar with the assistance that School Counseling services can provide to pupils and their families. The majority of the parent's place value on the potential help of the counselor in areas such as the integration of children in new environments and the construction of trustful relationships between children and teachers. Furthermore, most of the parents' responses indicate their belief that school counselling services could be of important and useful assistance to families and parents, especially in facilitating the improvement of the child-parent relationship and in playing an advisory role for pupils and their parents. Well over half of the participating parents (67\%) expressed their belief that school counselling would be helpful in the resolution of family problems but also of children's' behavioral problems. Our findings resonate with those of Grubbs (2013) in that the majority of our participants also placed greater value on the school counsellor's help in topics that fell more into the Personal/Social Development Domain of the ASCA National Model. Indeed, the parents of our sample were least interested in topics that fell into the learning difficulties and academic domain (22\%). Instead, they were more interested in knowing how to contribute to their children's personal and social development (e.g. by dealing with violent behaviors at school, $32 \%$ ), whether by learning parenting skills to contribute to that development or by helping their children develop better personal/social skills (e.g. cultivation of respect towards diversity, $40 \%$ ). This does not come as a surprise to us, as the elementary school years, especially the 4th, 5th and 6th grade is developmentally characterized by physical, social, and cognitive developmental changes that can be seen as physically and emotionally "awkward" or "difficult", as they often coincide with the child's entrance into pre-puberty (ages 9-12). The majority of the parents of our sample $(85 \%)$ stressed the important role of school counselors in early prevention as well as their belief that school counselling interventions will be more 
successful provided there is a good collaboration between the school, the parents, the pupils and the counsellor(s) (70\%), and provided that the counselling is not left to the teacher but is conducted by a qualified school counsellor $(82 \%)$.

\section{Conclusion}

More extensive research is critical to enhancing the field's current understanding of parenting styles and the role they play in child behavioral outcomes. An increased understanding of the roots of the diverse parenting practices, may enable us to address more effectively address the environmental factors that lead parents to adopt less ideal strategies. It is however important to use these research findings in developing more effective prevention and intervention programs at the public elementary school level in order to enhance parenting skills and consequently to increase parental effectiveness.

Parent Education Programs can strengthen parents' ability to manage a child's behavior, support socio-emotional development, and reduce child neglect and abuse. Studies of parental interventions have reported improved developmental outcomes of children, as well as parents' knowledge on child development. Because parenting programs have been found to demonstrate a sustained effect on early disruptive behavior problems on early disruptive behavior problems (Comer et al., 2015) it is important to ensure that such programs are available especially to atrisk-families and accessible at the public school of their child. Parents cannot be blamed for their shortcomings regarding their effectiveness in the parental role and practices they apply, or for their children's behavioral outcomes, but should instead be given the opportunities and the resources they need in order to learn the skills to perform better. If such opportunities and resources are available at their child's public elementary school, then they become more accessible for them. A good collaboration between the teacher, the counselor and the parents may help parents employ more appropriate parenting practices and thus promote the adaptive behavioral development of their children.

\section{References}

Akhter, N., Hanif, R., Tariq, N., \& Atta, M. (2011). Parenting Styles as Predictors of Externalizing and Internalizing Behavior Problems among Children. Pakistan Journal of Psychological Research, 26(1), 23-41.

Albrecht, A., Galambos, N., \& Jansson, S. (2007). Adolescents' internalizing and aggressive behaviors and perceptions of parents' psychological control: A panel study examining direction of effects. Journal of Youth and Adolescence, 36(5), 673-684.

American Psychological Association- APA, (2018). Parenting. Retrieved from: http://www.apa. org/topics/parenting/index.aspx

Aunola, K., \& Nurmi, J. (2005). The role of parenting styles in children's problem behavior. Child Development, 76(6), 1144-1159.

Barlow, J., Smailagic, N., Huband, N., Roloff, V., \& Bennett, C. (2014). Group-based parent training programmes for improving parental psychosocial health. Cochrane Database Syst Rev, 5, CD002020. https://doi.org/10.1002/14651858.CD002020.pub4

Baumrind, D. (1991). The influence of parenting style on adolescent competence and substance use. The Journal of Early Adolescence, 11(1), 56-95.

Booth, A., \& Hiau, J.K. (2009). Birth Order Matters: The Effect of Family Size and Birth Order on Educational Attainment. Journal of Population Economics, Vol. 22, (2), pp. 367-397

Bowers, J. \& Hatch, T. (2012). The ASCA National Model: A framework for school counseling programs (3rd edition). Alexandria, VA: American School Counselor Association. 


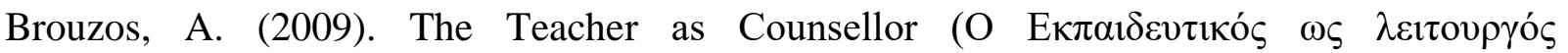
$\Sigma v \mu \beta о v \lambda \varepsilon v \tau i \kappa \eta ́()$. Athens:Gutenberg.

Calzada, E. J. (2001). Normative and optimal parenting in Dominican and Puerto Rican mothers of young children (Order No. AAI9984400). Available from PsycINFO. (619708281; 200195004303).

Child Welfare Information Gateway, (2019). Parent education to strengthen families and reduce the risk of maltreatment. Washington, DC: U.S. Department of Health and Human Services, Children's Bureau.

Chorpita, B. F., \& Barlow, D. H. (1998). The development of anxiety: The role of control in the early environment. Psychological Bulletin, 124(1), 3-21.

Comer, J., Furr, J., Cooper-Vince, C., Madigan, R., Chow, C., Chan, P., Idrobo, F., Chase, R., McNeil, C., Eyberg, S. (2015). Rationale and considerations for the internet-based delivery of parent-child interaction therapy. Cognitive and Behavioral Practice, 22(3), 302-316.

Conger, R.D, Ebert-Wallace, L., Sun, Y., Simons, R.L., McLoyd, V.C., \& Brody, G. (2002). Economic pressure in African American families: A replication and extension of the family stress model. Developmental Psychology, 38:179-193.

Coocklin, A., Giallo, R. \& Rose, N. (2011). Parental fatigue and parenting practices during early childhood: An Australian community surfy. Child Care Health Dev. (38) pp.654-64.

Crouter, A., McHale, S., \& Bartko, T. (1993). Gender as an organizing feature in parent-child relationships. Journal of Social Issues, Vol.49 (3), pp. 161-174.

Demetriou, L. \& Christodoulides, P. (2006). Parental Acceptance-Rejection in the Cypriot family. A Social Psychological Research on the PART/PARQ. The Cyprus Journal of Science and Technology, Vol. 5 (2), pp. 85-98.

Dimitriou, L. (2014). Comparative study of teachers and parents: The need of the integration of School Counseling in the Cyprus Elementary School. Review of Counseling and Guidance (107) pp. 38-52.

Downey, G. \& Coyne, J. (1990). Children of depressed parents: An integrative review. Psychological Bulletin, 108(1), 50-76.

Furlong, M., McGilloway, S., Bywater, T., Hutchings, J., Smith, S. M., \& Donnelly, M. (2012). Behavioral and cognitive-behavioral group-basedparenting programs for early-onset conduct problems in children aged 3 to 12 years. Cochrane Database Syst Rev, (2), CD008225. https://doi.org/10.1002/14651858.CD008225.pub2

Grubbs, N. (2013). School Counselor-Parent Collaborations: Parents' Perceptions of How School Counselors Can Meet their Needs. Dissertation, Georgia State University, 2013. https://scholarworks.gsu.edu/cps_diss/91

Hetherington, E.M, Henderson, S.H., Reiss, D. (1999). Adolescent Siblings in Stepfamilies: Family Functioning and Adolescent Adjustment. Monographs of the Society for Research in Child Development, 64(4), p. 222

Johnston, C. \& Mash, E.J. (1989). A measure of parenting satisfaction and efficacy. J Clin Child Psychol. 18(2), pp. 167-175.

Jones, T., \& Prinz, R. (2005). Potential roles of parentel self-efficacy in parent and child adjustment: A Review. Clin Psychol Rev, 25, pp. 341-363 
Kainuwa, A., \& Yusuf, N. (2013). Influence of Socio-Economic and Educational Background of Parents on their Children's Education in Nigeria. International Journal of Scientific and Research Publications, 3 (10).

Kaminski, J. W., Valle, L. A., Filene, J. H., \& Boyle, C. L. (2008). A meta-analytic review of components associated with parent training program effectiveness. Journal of Abnormal Child Psychology, 36(4), 567-589. doi: 10.1007/s 10802-007-9201-9

Kim, T., Connolly, J., Rotondi, M. \& Tamin, H. (2018). Characteristics of positive interaction parenting style among primiparou teenage, optimal age and advanced age mothers in Canada BMC Pediatrics (18).

Maccobi, E. (2000). Parenting and its Effects on Children: On Reading and Misreading Behavior Genetics, Annual Review of Psychology (51:1), 1-27.

Maccoby, E. \& Martin, J. (1983). Socialization in the context of the family: Parent-child interaction. Handbook of Child Psychology Vol. 4. Socialization, Personality, and Social Development, 4, 1-101.

Mistry, R.S., Lowe, E.D, Benner, A.D, Chien, N. (2008). Expanding the family economic stress model: Insights from a mixed-methods approach. Journal of Marriage and Family, (70) pp. 196- 209.

Patterson, G.R. \& Forgatch, M. (1995). Predicting future clinical adjustment from treatment outcome and process variables. Psychol. Assess. (7) 275-85.

Printham, K., \& Chang, A. (1989). What being a parent of a new baby is like: Revision of an Instrument? Res Nurs Health (12) pp. 323-289.

Rohner, R. P. (1991). Handbook for the Study of Parental Acceptance and Rejection. Storrs: Center for the Study of Parental Acceptance and Rejection.

Shelton, K. K., Frick, P. J., \& Wootton, J. (1996). Assessment of parenting practices in families of elementary school-age children. Journal of Clinical Child Psychology, 25(3), 317-329.

Wilder Research. (2016). The benefits of parenting education: A review of the literature for the Wilder Parent Education Center. Retrieved from https://www. wilder.org/wilderresearch/researchlibrary/ benefits-parenting-education-review-literature-wilderparent 